\title{
NASKAH DRAMA RAJAPATI KARANGAN AHMAD BAKRI (Kajian Struktural dan Pragmastilistik)
}

\author{
Zainah Asmaniah \\ Program Studi Pendidikan Bahasa dan Sastra Indonesia STKIP GARUT \\ Pos-el: zainahasmaniah87@ymail.com
}

\begin{abstract}
Abstrak
Penelitian ini bertujuan untuk mengetahui serta mendeskripsikan tiga hal yaitu: 1) cerita yang ada di dalam naskah drama Rajapati, 2) struktur yang ada di dalam naskah drama Rajapati, serta 3) pragmastilistik yang ada di dalam naskah drama Rajapati. Metode yang digunakan dalam penelitian yaitu metode deskriptif-analitis. Teknik yang digunakan dalam mengumpulkan data adalah teknik teks dan teknik dokumentasi. Kesimpulan dari hasil penelitian ini: 1) data naskah drama Rajapati terdiri dari 392 tuturan dialog, 16 halaman, satu babak, dan tujuh adegan; 2) struktur naskah terbagi dua yaitu struktur lahir dan struktur batin; dan 3) pragmastilistik terdiri dari dua unsur yaitu: pragmatik terbagi ke dalam 6 macam yaitu: asertif, direktif, komisif, deklaratif, serta ekspresif, sedangkan stilistik terdiri dari 2 unsur majas yang berdasarkan struktur kalimahnya terdiri dari 6 majas sedangkan berdasarkan lansung tidaknya makna terdiri dari 2 jenis yaitu retoris dan kiasan. Kedua-duanya masingmasing terdiri 7 majas. Kedua unsur tersebut digabung menjadi unsur pragmastilistik yang memiliki 19 pola verba perfomatif berdasarkan majas.
\end{abstract}

Kata kunci: naskah drama, struktural, dan pragmastilistik.

\section{THE SCRIPT OF THE PLAY RAJAPATI OF AHMAD BAKRI (The Study of Strukture and Pragmastylistics)}

\begin{abstract}
This study was aimed to determine and to describe 1) the characters, 2) the structure, and 3) the pragmastylistics in the script of the play Rajapati. The method used in this research was descriptive-analytic method. The data collection technique employed text engineering and technical documentation. There are several conclusions of this study. First, the script of the play Rajapati consists of 392 speech dialogs, 16 pages, one round, and seven scenes. Second, the structure of the text is divided into two, namely physical and mental structures. Third, the pragmastylistics consists of two elements: pragmatic and stylistic. The pragmatic elements are divided into 6 categories: assertive, directive, commissive, declarative, and expressive. The stylistic elements consist of two elements of the figure of speech: six figures of speech are based on the structure of the sentence; and two types of rhetorical and figurative based on meaning directness. Each of them has seven figures of speech. Both elements are combined into pragmastylistics elements, which contain 19 patterns of performative verbs based on the figures of speech.
\end{abstract}

Keywords: Script of play, Structure, and Pragmastylistics. 


\section{PENDAHULUAN}

Jawa Barat

kini banyak mempertontonkan dan mengadakan lomba seni pementasan drama Sunda. Hal ini dikarenakan masih banyak masyarakat yang menyukai serta menjaga keberlangsungannya kegiatan ini. Pengarang naskah drama banyak yang memasukan beberapa kejadian yang serupa dengan kehidupan sehari-hari yang menontonnya. Meskipun dalam naskah tersebut banyak mengandung pepatah atau sindiran yang menggurui, tetapi para penonton tetap memberikan apresiasi yang baik, serta menganggap karangan tersebut sangat menghibur.

Pemakaian bahasa dalam dialog naskah drama mengungkapkan segala hal dalam aspek kebahasaan terlebih lagi dari segi emosi. Dari mulai bertanya, menjawab, berbicara sendiri, tertawa, menertawakan, ditertawakan, memarahi, dimarahi, menangis, ditangisi, dan lain sebagainya. Bahasa di dalam naskah drama itu harus mencakup ke dalam tiga cara untuk mempengaruhi keinginan masyarakat, seperti yang telah disampaikan oleh Aristoteles yaitu ethos, logos, dan pathos.

Manfaat pragmastilistik di dalam kehidupan sehari-hari manusia adalah adanya seni dalam berbicara dalam kehidupan manusia, serta menjadi bahan untuk siapa saja yang menulis sebuah karangan naskah drama bahwa naskah drama itu isinya bukan hanya sekedar tuturan biasa. Tetapi memiliki sebuah nilai yang bisa dipelajari oleh kita bersama. Jika isi naskah itu merupakan pesan atau amanat yang berisikan berbagai nilai yang luhur. Selain itu, pastinya juga akan memperbanyak kajian kebahasaan, utamanya untuk mempelajari strategi, sistem, serta gaya bahasa yang digunakan dalam bahasa naskah drama. Selain dari pragmastilistik, struktural naskah drama pun harus dikaji dan dipelajari, karena akan lebih memperjelas bagian-bagian apa saja yang ada di dalam naskah drama.

\section{METODE}

Metode adalah langkah-langkah untuk mencapai tujuan hasil penelitian yang menyeluruh. Untuk itu, dalam setiap penelitian selamanya memerlukan metode agar bisa mencapai tujuan yang diinginkan. Metode yang digunakan dalam penelitian ini adalah metode deskriptif. Metode deskriptif digunakan dalam penelitian ini untuk mendeskripsikan secara sistematis data yang ada di dalam naskah drama rajapati berdasarkan kepada kajian struktural dan pragmastilistik.

Metode khusus yang digunakan dalam penelitian ini yaitu metode struktural dan pragmastilistik. Metode ini merupakan gabungan antara metode penelitian struktural-pragmastilistik.

Pada pelaksanaannya, penggunaan metode struktural-pragmastilistik itu adalah untuk menganalisis struktur batin dan lahir, serta kajian pragmastilisnya.

\section{HASIL DAN PEMBAHASAN \\ Pengertian Naskah Drama}

Rusyana (1987, hal. 140) menyebutkan bahwa naskah drama merupakan sebuah karangan tertulis yang berisikan sebuah cerita atau kisah yang menggambarkan kehidupan serta watak pemain untuk kebutuhan satu pagelaran atau pementasan drama.

Teks naskah drama biasanya merupakan sebuah dialog yang menjadi bagian paling penting dari sebuah drama, dilihat dari segi ini bisa disebutkan bahwa naskah drama itu sebuah karangan dialog. Dialog ini dibentuk oleh kalimat langsung yang diucapkan oleh seorang pemain beserta pemain yang lainnya. Saling bergantian. Setiap pembicaraan pasti memiliki maksudn misalnya: menyuruh, bertanya, menuntut, menolak, meminta, dan lain sebagainya. Selain dari adanya maksud yang dituju, setiap pembicaraan juga mengungkapkan pikiran, perasaan, serta tingkah laku dari setiap tuturannya (Rusyana, 1987, hal. 141). 
Selain dialog, ada juga ucapan yang ditunjukkan untuk dirinya sendiri. Seperti curahan hati (monolog). Dari setiap curahan hati, seseorang bisa menghayati terhadap apa saja yang menjadi isi batin seseorang.

Dari sebuah dialog yang diucapkan, seseorang bisa memahami hal-hal apa saja yang akan terjadi di kemudian hari. Selain itu juga bisa mengetahui sifat seseorang serta keadaan yang terjadi pada saat itu.

Di dalam sebuah naskah drama, dialog banyak sekali kegunaannya. Hal ini bisa dilihat ketika seseorang membacakan naskah dialog dengan penuh penghayatan serta dengan suara yang sesuai dengan karakter dalam naskah drama tersebut, maka pemain akan merasakan luapan perasaan yang sebelumnya tidak pernah terungkapkan. Biasanya dalam membaca dialog naskah drama kita harus membacakannya dengan suara lantang, harus bisa mengatur tinggi rendahnya suara, harus bisa mengatur tinggi rendahnya nada, serta cepat tidaknya ritme dalam membaca. Apalagi ketika sedang bermain di atas pentas, pemain harus bisa mengatur tinggi rendahnya irama.

\section{Struktur Naskah Drama}

Rusyana (1987,

hal. 138) mengemukakan wujud lahiriah sebuah naskah drama adalah hal-hal fisik yang dimiliki sebuah naskah drama, seperti beberapa hal di bawah ini:

1. Penokohan pemain, yaitu hal-hal yang menjadi identitas seorang pemain. Baik itu berkaitan dengan sifat, keadaan fisik, karakter, serta kemampuan pemain di cerita tersebut.

2. Babak dan adegan, adalah bagianbagian yang membagi karangan drama. dalam satu babak bisa diperankan berbagai kejadian di satu tempat, bahkan dalam satu waktu yang sama. Setiap babak dibagi lagi menjadi beberapa adegan, mengikuti alur berubahnya kejadian dengan cara datang atau perginya seorang pemain. Ada drama yang dibangun oleh satu babak serta ada juga drama yang dibangun oleh beberapa babak.

3. Candraan di awal babak, menceritakan keadaan latar, suasana, pemain, kejadian, dan lain sebagainya. Biasanya tidak hanya sebagai keperluan semata, serta bukan sebuah gambaran yang mendetail. Selain di awal babak, yaitu sebelum dialog, disela-sela dialog itu selalu ada petunjuk mengenai tingkah laku pemain. Candraan di awal babak serta petunjuk dalam naskah drama ditulisnya menggunakan hurup miring, berbeda dengan dialog yang ditulisnya menggunakan hurup tegak biasa.

4. Dialog, adalah kalimat langsung dari para pemain yang saling bersahutan satu sama lain. Dari mulai ditulis namanya, ditandai dengan titik dua, disana dituliskan tuturan para pemain. Bagian besar dari sebuah karangan drama adalah dialog. Singkatnya, dialog itu merupakan bagian yang sangat penting dalam sebuah naskah drama.

5. Latar (setting), adalah tempat yang digambarkan dalam cerita drama tersebut. Bagaimana keadaan atau situasinya, serta waktu kejadiannya pun merupapakan bagian penting dari latar dalam sebuah naskah drama.

6. Prolog dan epilog. Prolog adalah tulisan yang iasanya menjadi pengantar dalam sebuah karangan drama. bagian ini diisi oleh sebuah keterangan atau penemuan pengarang mengenai laporan yang sedang diceritakan. Bisa dibandingkan dengan rajah pramuka dina carita pantun. Epilog ditulis sebagai penutup naskah drama, diisi oleh kesimpulan laporan serta nasihat pengarang, bisa dibandingkan dengan rajah penutup dalam cerita pantun. Dalam hal ini banyak juga drama yang tidak menggunakan prolog dan epilog.

Selain itu juga Rusyana (1987, hal. 142) menambahkan adanya struktur batin yang yang bisa diinterpretasikan berbedabeda oleh pembaca serta terdapat di dalam naskah drama, yaitu (1) tema (dasar dari 
sebuah cerita drama) dalam naskah drama memiliki unsur-unsur pokok ketika menghasilkan sudut pandang yang berbedabeda untuk pembaca merupakan hal yang sangat penting; (2) rasa, yaitu perasaan yang bisa dirasakan oleh pembaca ketika membaca naskah tersebut; (3) nada, yaitu interpretasi yang sedang membaca ketika membacakan cerita tersebut; serta (4) amanat, yaitu satu hal yang sangat penting yang harus disampaikan oleh pengarang untuk para pembaca.

\section{Pengertian Pragmastilistik}

Istilah "pragmastilistik" merupakan kajian antardisiplin antara paragmatik dan stilistika. Pragmatik yaitu kajian yang menghubungkan antara struktur bahasa dengan pemakainya (Cristal dalam Nurhadi, 2013, hal. 15), atau telaah mengenai kondisi-kondisi umum pemakaian komunikasi bahasa (Levinson, 1983, hal..21), sedangkan stilistika yaitu ilmu yang membahas mengenai bahasa yang digunakan dalam karya sastra; ilmu antardisiplin antara linguistik dan kesusastraan; penerapan linguistik dalam penelitian gaya bahasa (Kridalaksana dalam Nurgiyantoro, 2014, hal.23). pragmatik berpusat terhadap pemakaian bahasa dalam konteks situasi, sedangkan stilistika berpusat pada pemakaian bahasa dalam satu tuturan yang lazim disebut maksim (Leech, 1983, hal. 32). Oleh sebab itu pragmatik dan stilistika saling berkaitan satu sama lain. Dalam beberapa tahun terakhir ini, pragmatik dan stilistika sama-sama membahas tuturan yang menghasilkan satu kajian yang disebut pragmastilistik.

Kaitanya dengan pragmastilistik, ( Hickey dalam Nurhadi, 2013, hal. 15) menyebutkan beberapa pandangan di antaranya yaitu:

1. Pragmastilistik yaitu gaya bahasa yang ditambahkan komponen pragmatik ke dalam pembahasannya.

2. Pragmastilistik memberikan perhatian khusus terhadap fitur-fitur yang dipilih saja oleh pembicara, tetapi memilih cara yang tujuannya jelas serta cara menyampaikannya berbeda.

3. Pragmastilistik melibatkan seluruh aspek yang berkaitan dengan kondisi linguistik serta ekstra linguistik, yang memungkinkan adanya unsur-unsur konteks untuk menghasilkeun teks yang merubah struktur internal pada keadaan, pikiran, serta pengetahuan.

4. Jika linguis tertarik untuk bertanya " What do you say?" 'kamu berbicara apa?', ahli stilistika akan bertanya "How do you say?" " bagaimana anda bercerita?" ahli pragmatik akan bertanya "What do you do?" 'apa yang dilakukan oleh anda', ahli pragmastilistik akan bertanya "How do you do?" "bagaimana anda melakukannya?'.

Berdasarkan penjelasan di atas bisa disimpulkan bahwa kajian pragmastilistik itu adalah merupakan gabungan antara pragmatik dan stilistika yang membahas gaya bahasa yag dilihat dari segi aspekaspek pragmatik seperti dalam tuturan dan konteks situasinya. Selain dari itu, pragmastilistik tidak hanya sekedar membahas maksud pembicaraan, tetapi juga membahas bagaimana maksud pembicaraan. Tetapi juga membahas cara melakukan sebuah tindakan.

\section{Komponen Pragmatik}

Hickey (dalam Nurhadi, 2013, hal.16) menyebutkan bahwa pragmatik secara langsung bukan membahas bahasa, tetapi membahas apa yang dilakukan oleh manusia ketika sedang menggunakan bahasa, kegunaan, serta pemakainya. Selain itu juga pragmatik membahas cara pemakain bahasa agar menjadi komunikasi yang efektif.

Pragmatik dan sémantik sama-sama menggunakan makna sebagai isi dalam komunikasi. Sémantik berpusat pada pikiran (competence langue), sedangkan pragmatik berpusat terhadap pembicaraan (perfomance, parole). Sebagaimana yang disebutkan oleh (Levinson, 1983, hal. 9) bahwa "pragmatics is concerned solely with 
perfomance principle of language usage and the disambiguition of sentence by the context in which they were uttered". Selian itu, (Levinson, 1983, hal. 9) juga mendefinisikan pragmatik sebagai studi bahasa yang menelaah rélasi bahasa serta konteks yang tergramatisasi dan terkodifikasi agar tidak lepas dari struktur bahasanya.

\begin{tabular}{llr}
\multicolumn{2}{c}{ Beberapa batasan mengenai } \\
pragmatik. \\
antaranya:
\end{tabular}

1. Pragmatik yaitu studi mengenai maksud pembicara;

2. Pragmatik yaitu studi mengenai makna kontekstual;

3. Pragmatik yaitu studi mengenai bagaimana caranya agar banyak hal yang disampaikan dari pada yang dibicarakan;

4. Pragmatik yaitu studi mengenai ungkapan jarak serta hubungan; dan

5. Pragmatik yaitu studi mengenai hubungan antara bentuk-bentuk linguistik dengan pemakaian bentukbentuk tersebut.

Deskripsi mengenai hubungan itu dibahas oleh Searle (dalam Nurhadi, hal. 38) terhadap tipe tindak tutur ilokusi yang diklasifikasikeun terhadap lima macam bentuk tuturan yang dilihat dari fungsi komunikatifnya. Kelima macam bentuk tuturan itu bisa dirangkum ke dalam deskripsi di bawah ini. (1) Asertif (assertives) atau réfrésentatif (representatives), yaitu tindak tutur yang membuat pembicaranya mengungkapkan apa saja yang seharusnya diungkapkan, misalnya: menyatakan (stating), menyarankan (sugesting), membual (boasting), mengeluh (complaning), serta mengklaim (claiming). (2) Diréktif (directives), yaitu tuturan yang dibuat oleh pembicara agar mempunyai pengaruh terhadap pendengar agar melakukan sebuah tindakan, dalam arti lain menyuruh kepada orang lain agar melakukan sebuah pekerjaan, misalnya: memesan (ordering), memerintah (commanding), meminta (requesting), menasihati (advising), serta merekomendasikan (recomending); (3) Éksprésif (expressives), yaitu tuturan yang memiliki fungsi untuk menyatakan atau menunjukan sikap psikologis pembicara terhadap sebuah keadaan, misalnya: berterima kasih (thanking), mengucapkan selamat (congratulating), meminta maaf (pardoning), menyalahkan (blaming), memuji (praising), dan belasungkawa (condoling); (4) Komisif (commisives), yaitu tuturan yang fungsinya menyebutkan janji atau menawar sesuatu yang imbasnya ada hubungannya di masa yang akan datang, misalnya: mengucapkan janji (promising), mengucapkan sumpah (vowing), serta menawarkan satu hal (offering), dan (5) Déklarasi (declarations), yaitu tuturan yang menghubungkan antara isi tuturan dengan kenyataannya, misalnya: pasrah (resigning), mengeluarkan (dismissing), membabtis (christening), memberi nama (naming), mengangkat (appointing), mengucilkan (excommunicating), serta menghukum (sentencing).

\section{Komponen Stilistika}

Stilistika (stylistic) merupakan ilmu yang membahas mengenai gaya, sedangkan stil (style) merupakan cara-cara yang has, bagaimana segala hal dituturkan menggunakan cara tertentu serta tujuan yang dimaksudkan bisa diperankan secara maksimal (Ratna, 2009, hal. 3). Sesuai dengan pendapat itu (Turner, 1973, hal. 7) mengemukakan juga bahwa stilistika merupakan bagian linguistik yang memusatkan kajiannya terhadap macammacam pemakaian bahasa yang kompleks dalam karya sastra.

Pernyataan itu diikuti juga oleh (Cummings dan Simmons, 1986, hal. 34) mengungkapkan bahwa kajian yang mengorientasikan terhadap linguistik disebut stilistika. Ditambahkannya juga stilistika menjadi bagian cabang linguistik. Cumming dan Simmons memberikan contoh kajian linguistik itu terhadap 
pedoman tiori linguistik sistemik Halliday terhadadap sebuah puisi. Sangat terlihat Cummings dan Simmons mengikuti jejak langkah Halliday sendiri dalam mengkaji puisi.

Dalam penerapannya ada dua majas yang digunakan dalam mengkaji naskah drama rajapati, yaitu berdasarkan struktur kalimatnya serta berdasarkan langsung dan tidaknya makna.

\section{Majas berdasarkan Struktur Kalimah}

Melihat dari segi struktur kalimahnya, majas terbagi ke dalam lima macam, yaitu klimaks, anti klimaks, paralelisme, antitesis, dan repetisi. Kelima majas ini dipaparkan seperti di bawah ini:

1. Klimaks

Menutut Kéraf (2009: hal.124) klimaks adalah prosés menggambarkannya urutan-urutan pikiran yang semakin lama semakin meningkat. Klimaks bisa juga disebut sabagai gaya bahasa yang memiliki urutan-urutan pikiran yang semakin lama semakin meningkat kepentingannya dari gagasan-gagasan sebelumnya.

\section{Antiklimaks}

Menurut Nurgiyantoro (2014: hal. 272) antiklimaks adalah proses yang menggambarkan urutan-urutan pikiran yang semakin lama semakin menurun. Hal ini hanya sebatas maslah gaya, cara, atau strategi untuk menarik perhatian pembaca dan pendengar. Jadi, mau meningkat atau menurun tunjuannya hanya sekedar menunjukkanakan pentingnya tuturan yang ingin disampaikan.

\section{Paralelisme}

Menurut Ratna (2009: hal. 441) paralelisme adalah majas yang menggambarkan kesejajaran unsur-unsur dalam sebuah konstruksi, mau itu kesejajaran dalam kata frasa yang fungsinya sama. Selain dari itu bisa menghubungkan satu tuturan dengan tuturan yang lainnya.
4. Antitesis

Menurut Keraf (2009: hal. 126) antitésis adalah gaya bahasa yang memiliki gagasan-gagasan yang bertolak belakang, serta menggunakan kata atau kelompok kata yang bertolak belakang juga. Selain dari itu Nurgiyantoro (2014: hal. 273) mengemukakan bahwa ada satu kemiripan antara antitesis dengan paralelisme, dan di dalam teks sastra bentuk seperti ini yang banyak terlihat.

\section{Repetisi: Epizeuksis}

Menurut Ratna (2009: hal. 442) Epizeuksis adalah pengulangan kata, frasa, atau kalimat secara langsung. Yang memiliki tujuan untuk menguatkan sebuah pertanyaan agar lebih jelas.

\section{Majas berdasarkan Langsung tidaknya Makna}

Melihat majas yang berdasarkan langsung tidaknya makna bisa terbagi ke dalam dua macam yaitu gaya bahasa retoris dan gaya bahasa kiasan.

Gaya bahasa retoris menurut Kéraf (2009, hal.130) terbagi kedalam sembilan majas, di antaranya adalah:

\section{Asindeton}

Menurut Kéraf (2009: hal.131) asindeton adalah sebuah gaya bahasa yang mengacu terhadap acuan yang sifatnya padat. Cirinya ada beberapa kata, frasa, atau klausa yang sederajat yang tidak dihubungkan oleh kata sambung. Bentuk ini biasanya dipisahkan oleh koma.

\section{Polisindeton}

Menurut Kéraf (2009: hal.131) polisindeton adalah kebalikannya asindeton. Beberapa kata, frasa, atau klausa yang berurutan dihubungkan oleh kata sambung. yaitu kabalikanana asindéton. Penggunaan konjungsi dianggap penting untuk menyatakan suatu hubungan. Beda dengan asindeton yang lebih mengutamakan kata, frasa, atau klausa yang dihubungkannya. 
3. Prolepsis atau Antisipasi

Menurut Ratna (2009: hal.447) prolepsis atau antisipasi adalah kata yang mendahului kejadian yang sebenarnya. Majas ini memiliki kerangka pemikiran yang mendahului kejadian yang sebenarnya.

\section{Erotesis}

Erotesis adalah majas yang diungkapkan berupa bentuk pertanyaan yang tidak memerlukan jawaban, tetapi respons yang baik berupa perbuatan atau sikap.

\section{Bombastis}

Menurut Ratna (2009: hal.440) bombastis adalah pemakaian keterangan atau penjelasan secara berlebihan.

\section{Kontradiksio}

Ratna (2009: hal.446) mengungkapkan bahwa kontradiksio merupakan majas yang bertolak belakang secara situasional serta termasuk ke dalam majas pertentangan.

\section{Hiperbola}

Menurut Baldic (dalam Nurgiyantoro, hal.260) hiperbola adalah gaya yang melebih-lebihkan suatu hal yang dimaksudkan untuk membandingkan keadaan yang sebenarnya serta lebih menekankan kepada penuturnya.

\section{Litotes}

Menurut Nurgiyantoro (2014: hal.265) litotes adalah kebalikannya dari majas hiperbola. Jika hiperbola melebih-lebihkan, maka litotes mengecilkan atau meniadakan fakta-fakta yang ada.

\section{Paradoks}

Menurut Nurgiyantoro (2014: hal. 267) paradoks adalah gaya bahasa yang menghadirkan unsur pertentangan secra eksplisit di dalam pembicaraannya. Tetapi hal ini dimaksudkan sebagai suatu cara atau strategi agar lebih menekankan, menegaskan, dan mengintensifkan suatu hal yang dituturkannya. Padahal yang sebenarnya tidak seperti itu.

Gaya bahasa kiasan menurut Kéraf (2009) terbagi ke dalam enam hal di antaranya yaitu:

\section{Simile}

Menurut Keraf (2009, hal.138) simile merupakan majas perbandingan yang sifatnya eksplisit, yaitu membandingkan yang langsung, serta menyebutkan hal yang serupa dengan hal lain yang diungkapkan melewati kata-kata ini, seperti, sama, sebagai, bagaikan, dan laksana.

\section{Metafora}

Menurut Baldic (dalam Nurgiyantoro, 2014, hal.224) metafora merupakan majas yang paling sering terbaca dalam beberapa teks sastra. Metafora juga merupakan benta bahasa figuratif yang penting. Metafora juga dituturkan secara implisit.

\section{Alegori}

Menurut Nurgiyantoro (2014: hal.239) alegori merupakan majas yang di dalamnya ada unsur yang mebandingkan dan unsur yang dibandingkannya. Dalam prinsipnya majas alegori termasuk ke dalam majas perbandingan.

\section{Personifikasi}

Menurut Nurgiyantoro (2014: hal.235) personifikasi merupakan bentuk pemajasan yang mempunyai sifat benda yang mati serta sifat-sifat manusia. Artinya, sifat yang diberikan itu sebenarnya hanya dimiliki oleh manusia, bukan benda-benda mati, serta sifat manusia yang memiliki akal.

\section{Sinekdoke}

Istilah sinekdoke berasal dari bahasa Yunani synekdechsthai yang artinya 'saling menerima'. Majas sinekdoke menurut Kéraf (2009, hal.142) mengemukakan bahwa sinekdoke adalah semacam bahasa figuratif yang memakai sebagian hal untuk menyebutkan keseluruhannya. 


\section{Metonimia}

Menurut Nurgiyantoro (2014, hal.243) metonimia merupakan suatu ungkapan yang menunjukan adanya keterikatan antara kata yang disebutkan dengan makna yang sebenarnya.

\section{Ironi}

Menurut Nurgiyantoro (2014, hal.269) gaya ironi merupakan sebuah pembicaraan yang maknanya kontras. Gaya ini dipakai untuk meninggalkan suatu hal yang sifatnya ironi seperti menyindir, mengkritik, mengancam, dsb.

\section{SIMPULAN}

Naskah drama merupakan sebuah dasar dalam membuat sebuah pementasan drama. selain itu naskah juga merupakan salah satu sarana pendidikan dan penelitian yang besar sekali manfaatnya. Atas dasar pemikiran yang seperti itulah, seorang pengarang tidak boleh seenaknya dalam menulis atau mengarang sebuah naskah drama jika dia tidak memiliki kemampuan dalam segi kebahasaan.

Adanya kemampuan dalam hal kebahasaan dalam menulis satu naskah akan menjadikan seorang pengarang lebih bebas dalam mengemukakan semua pesan yang ingin dia sampaikan. Artinya kemampuan kesastraan yang dimilikinya akan sejalan dengan kemampuan kebahasaannya. Pada saat ini, ada satu gagasan baru yang berkenaan dengan pragmastilistik dalam naskah drama, yaitu bagaimana cara seorang pengarang menggunakan kemahirannya dalam berbahasa ketika menulis satu naskah dibarengi dengan penggunaan gaya bahasanya. Agar mudah untuk ditafsirkan oleh pembaca bukan hanya dari segi kesastraannya saja yang terus-terusan membahas strutural naskah drama, melainkan segi kebahasaannya yang berkaitan dengan pragmastilistik juga harus dikaji.

\section{DAFTAR PUSTAKA}

Cummings, M. dan Simmons, R. (1986). The Language of Literature. England: Pergamon Press Ltd.

Keraf, Gorys. (2009). Diksi dan Gaya Bahasa. Jakarta: Gramedia Pustaka Utama.

Leech, Geoffrey. (1983). Prinsip-prinsip Pragmatik. Jakarta: Penerbit Universitas Indonesia.

Levinson, Stephen C. (1983). Pragmatics. Cambridge: Cambridge University Press.

Nurgiyantoro, Burhan. (2014). Stilistika. Yogyakarta: UGM Press.

Nurhadi, Jatmika. (2013). Pragmastilistika Bahasa Indonesia (Kajian Tuturan Hipnoterapi). Tidak dipublikasikan. Tesis UNPAD.

Ratna, Kutha Nyoman. (2009). Stilistika: Kajian Puitika Bahasa, Sastra, dan Budaya. Yogyakarta: Pustaka Pelajar.

Rusyana, Yus. (1987). Payungsi Sastra. Bandung: Rahmat Cijulang.

Turner. G. W. (1973). Text, Context, Pretext: Critical Issues in Discourse Analysis. Oxford: Blackwell Publishing.

\section{UCAPAN TERIMA KASIH}

Penulis mengucapkan terima kasih kepada pembimbing hingga penelitian ini selesai. Tidak lupa ucapan terima kasih dan penghargaan setinggi-tingginya penulis sampaikan kepada penyunting Jurnal Lokabasa yang telah memuat tulisan ini. Untuk rekan seperjuangan terima kasih yang sebesar-besarnya atas segala bantuannya. 